\title{
Experimental test of a new compressed natural gas direct injection engine
}

\begin{abstract}
This paper presents experimental test results of a new compressed natural gas direct injection (CNGDI) engine that has been developed by modifying a multicylinder gasoline port injection engine. The major modifications done are (1) a modification of the injection system to gas direct injection using new high-pressure gas injectors, (2) a change of the compression ratio from 10 to 14 through modification of piston and cylinder head, (3) and new long edge spark plugs. The CNG pressure at the common rail is kept constant at 20 bar. The engine has been operated at wide open throttle (WOT) condition to compare all the results with the original base engine. Hence, two engines are tested in this investigation. The test was conducted on a computer-controlled dynamometer to measure brake power; specific fuel consumption; volumetric efficiency; and exhaust emissions such as carbon monoxide (CO), oxides of nitrogen (NOx), and unburned hydrocarbon (HC). The objective of this investigation is to compare the test results between a CNGDI engine and a gasoline engine. It was found that the CNGDI engine produces a $4 \%$ higher brake power at $6000 \mathrm{rpm}$ as compared to the original gasoline-fueled engine. The average brake specific fuel consumption (BSFC) of the CNGDI engine was slightly lower (about $0.28 \%$ ) than the base engine. The CNGDI engine reduces 50\% NOx emission as compared to base engine. However, the CNGDI engine produces higher $\mathrm{HC}$ and $\mathrm{CO}$ emissions as compared to the base engine by 34 and $48 \%$, respectively. The results of this experiment will be used to further improve the CNGDI engine as well as to develop a new CNGDI car. The detailed results including fuel mapping are presented with discussions.
\end{abstract}

